\title{
Exploration archives and indigenous histories: An introduction
}

\section{Shino Konishi, Maria Nugent and Tiffany Shellam}

Since the 1990s, a number of scholars have sought to uncover 'hidden histories' of exploration, as Felix Driver and Lowri Jones have referred to it. ${ }^{1}$ Working against a conventional emphasis on the exploits and achievements of the singular heroic explorer, imperial and colonial exploration is recast as a collective enterprise involving a diverse labour force and upon which expeditions were dependent for their progress and success. ${ }^{2}$ Various approaches are pursued for writing a more representative history of exploration, such as recuperating from the archives the stories of little- or lesser-known participants; rewriting histories of particular expeditions through the lens of their encounters and interactions with indigenous people; or giving greater prominence to the work of intermediaries of many kinds, including interpreters, brokers, guides, porters and other labourers. ${ }^{3}$ The result is a more complex and multivocal account of the practices and politics of European exploration, the social and historical contexts in which it occurred, and the relationships, networks and institutions it created and on which it depended.

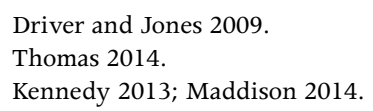


This book contributes to these reinterpretations of exploration history by turning our attention to the 'indigenous intermediaries', such as professional guides or other labourers who accompanied expeditions. ${ }^{4}$ They, as Dane Kennedy has recently argued, 'helped to make expeditions much more complex and culturally hybrid enterprises than conventional accounts suggest'. ${ }^{5}$ In taking this focus, we seek to build not only on Kennedy's comparative work on British exploration in Australia and Africa, but also on the earlier histories by Henry Reynolds and Don Baker, among others, which identified the crucial contribution made by Aboriginal people to Australian exploration. ${ }^{6}$ But our project goes beyond historical recuperation and belated recognition. We are interested in understanding the historically situated processes and practices of 'mediation', particularly within cross-cultural encounters and exchanges. In this respect, this volume of essays articulates with other contemporary scholarly interest in the go-betweens, brokers, agents, diplomats, negotiators or other intermediaries who operated in diverse imperial and colonial contexts in different parts of the globe and at different points in time. ${ }^{7}$

In their introduction to The Brokered World: Go-Betweens and Global Intelligence, 1770-1820, Simon Schaffer, Lissa Roberts, Kapil Raj and James Delbourgo define the 'go-between' as 'not just a passer-by, or a simple agent of crosscultural diffusion, but someone who articulates relationships between disparate worlds or cultures by being able to translate between them' ${ }^{8}$ They observe that histories of trade and commerce, of international relations and diplomacy, of religious contact and conversion, and of scientific travellers and knowledge production have all contributed to teasing out the crucial role that such intermediaries played in 'making sustained encounter and interaction across different cultures possible throughout history'. ${ }^{9}$ In their aim to go beyond Western representations of the 'other' and to investigate interactions between 'mobile figures', they recognise that the 'go-between' is key. Intermediaries of many kinds were, they insist, instrumental in creating new kinds of 'knowledge spaces', even though the vital work of translation and mediation they performed has 'become strangely obscured'. ${ }^{10}$

\footnotetext{
4 A companion volume, Shellam et al. (eds), Brokers and Boundaries: Colonial Exploration in Indigenous Territory, is forthcoming.

5 Kennedy 2013: 193.

Reynolds 1990; Baker 1998.

See: Metcalfe 2005; Schaffer et al. 2009; Ballantyne 2013, 2015; Merrell 1999; White 1991; Murphy 2003;

McDonnell 2009; Kennedy 2013.

8 Schaffer et al. 2009: xiv.

9 Schaffer et al. 2009: xi.

10 Schaffer et al. 2009: xv.
} 
This work on 'go-betweens and global intelligence' articulates with other historical studies that are more focused on the part intermediaries played in forging new relationships between indigenous people and newcomers within the borderlands of imperial and colonial frontiers. North American studies have been particularly influential here, notably the work of Richard White (not to be confused with the Australian historian by the same name who co-authored Chapter 3 in this volume) and his now widely applied concept of the 'middle ground', as well as James Merrell's studies on the people and places involved in brokering relations between 'natives and newcomers' on the Pennsylvania frontier from the 1680s to the mid-eighteenth century. ${ }^{11}$ White has memorably described the 'middle ground' as both a process and a space where different peoples come together and 'adjust their differences through what amounts to a process of creative, and often expedient, misunderstandings' ${ }^{12}$ These are the 'spaces' where intermediaries are typically found. As Merrell observes, 'wherever and whenever different peoples have met, there one finds a go-between'13 or 'go-betweens', plural, because, as White emphasises, the role can be assumed by groups as much as individuals. The focus on intermediaries and the work they do to articulate across different cultures and to forge new communities and alliances has been fruitfully extended into later historical studies of the United States of America. Studies by Michael McDonnell and Lucy Eldersveld Murphy are two notable examples. Each gives particular attention to the role that women played. McDonnell, for instance, identifies women's mobility as key to their work as cultural brokers, while Murphy suggests that Metis women were able to exploit 'overlapping ideals of womanhood common to both Anglos and Native-descended people' as they sought to create new alliances, families and communities. ${ }^{14}$

The North American scholarship is matched by a growing scholarship on southern hemisphere colonies, such as Alida Metcalfe's important study of go-betweens in the colonisation of Brazil in the sixteenth century. Her study examines a diverse range of 'go-betweens' and the different kinds of brokering they performed. She disaggregates the go-between on Brazil's colonial frontiers into three types, ${ }^{15}$ but it is her second category, which covers the 'transactional' work of translation, negotiation and cultural brokerage, that is closest to our own interests. Likewise, Tony Ballantyne's recent study of early colonial New Zealand, Entanglements of Empire, gives particular attention to processes of crosscultural translation and knowledge production and exchange. He highlights what he calls 'strategic intimacies' cultivated by male colonial agents with 'elite




colonised men' as crucial to the knowledge economy upon which colonial states depended 'as they worked to extend their sovereignty, map colonised terrains, know their subject peoples and consolidate their authority ${ }^{\prime}{ }^{16}$

Exploration was a key site of imperial and colonial knowledge production. How indigenous intermediaries engaged in exploration shaped 'the production and circulation of knowledge' is a question that Dane Kennedy explores in the chapter he devotes to them in his The Last Blank Spaces: Exploring Africa and Australia. ${ }^{17}$ A comparative approach allows him to delineate the knowledge and skills for which local indigenous guides and other labourers were valued in each context. In Australia, a guide's ability to read and navigate terrain was paramount, but less important in African contexts where expeditions followed established roads and trade routes, for instance. He argues that their superior knowledge and skills made Aboriginal guides highly valued by explorers in Australia. ${ }^{18}$ But he offers a more circumspect assessment of their value as intermediaries, when he writes that the contributions these intermediaries made as cultural brokers usually elicited a more ambivalent response', not least because in the absence of shared language and deep knowledge of cultural practices and protocols explorers were 'rarely certain they were speaking and acting on their behalf' ${ }^{19}$

Not surprising then, the matter of an intermediary's own identity - and of the nature and politics of their allegiances and alliances - can not be taken as given or fixed. As Felix Driver notes in his chapter in this volume, it is 'apparent that the people explorers often relied most upon for "local knowledge" were strictly speaking neither "local" nor "indigenous"'. The themes of allegiance and identity are also discussed in chapters by Maria Nugent and Tiffany Shellam. Thrown into doubt, then, are questions of who was leading whom. As D. Graham Burnett reveals in his study of Royal Geographical Society expeditions in British Guiana, these expeditions were typically accompanied by large numbers of Amerindian guides, translators, political intermediaries and porters, even though they were rarely mentioned in published accounts. Moreover, it was most likely that rather than accompanying the explorers, the explorers were adjuncts to the regular, seasonal Amerindian journeys. ${ }^{20}$

Important as a focus on intermediaries is for revising histories of imperial and colonial exploration, it is not without its methodological and interpretive challenges. A characteristic of current scholarship is, then, methodological

16 Ballantyne 2013: 7.

17 Kennedy 2013: 163.

18 Kennedy 2013: 177-178. For different conclusions drawn from a comparison between expeditions in Australia and the United States of America, see Baker 1995.

19 Kennedy 2013: 164.

20 Burnett 2002. 
innovation, aimed at addressing difficulties in detecting, recovering and interpreting the lives, histories and contributions of indigenous intermediaries and other 'marginal' participants whose presence and contribution have been 'strangely obscured'. These challenges are almost universally noted, for most scholars now recognise that indigenous people were not simply overlooked by historians of exploration, but were often deliberately effaced in published explorer accounts. ${ }^{21}$ Even when the presence of others was admitted, their contributions to the exploration enterprise and its outcomes would invariably be obscured by their being reduced to 'mere servants' or 'unnamed assistants' ${ }^{22}$ Alternatively, there was little or no acknowledgement of 'native' and 'local' knowledge in the natural histories, geographic studies and cartography produced by Europeans, as John Gascoigne's, Hilary Parsons's and Bronwen Douglas's chapters in this volume all illustrate. Moreover, colonial textual practices typically obscured the fragility of the European explorer and their deep dependence on indigenous intermediaries by depicting the 'natives' as fragile, immature, ignorant, and in need of European civilisation, as Burnett and others have observed. ${ }^{23}$ Gascoigne illuminates explorers' reliance on Aboriginal intermediaries - such as Moowattin, Calgood, Bungaree, ${ }^{24}$ Bagra and Nanbaree - who assisted in the collection of knowledge about indigenous botany. His chapter reminds us how colonial knowledge - ethnographic, cartographic or botanical information - was generated, being 'co-produced' by explorers and local indigenous people who shared and brokered information..$^{25}$ In this way, his work articulates with a much broader scholarship which traces the circuits of imperial intelligence and knowledge production across the eighteenth and nineteenth centuries. ${ }^{26}$ Re-reading exploration archives with and alongside indigenous knowledge of country can work to correct such projections and misrepresentations, as the chapter by Len Collard and Dave Palmer demonstrates.

The contributions to this volume share a concern with questions of how to recover and interpret the experiences, histories, biographies and legacies of indigenous people involved in exploration in Australia and further afield using Western/imperial-authored sources and repositories. A number of approaches are canvassed, all engaging in different ways with the limits and possibilities of what Driver refers to in his chapter as 'the archives of exploration'. Aware of the challenges of interpreting indigenous people's presence, agency, autonomy, authority and experience, often in the absence of their own accounts or with

\footnotetext{
Driver and Jones 2009.

Fritsch 2009.

Burnett 2002.

Bungaree is the mostly widely used spelling of his name, but it has other variants. Shellam in her chapter in this volume uses an alternative spelling: Boongaree.

25 Schaffer et al. 2009; Clark 2008.

26 Bayly 1996; Schaffer et al. 2009; Roque and Wagner 2011.
} 
only fragmentary evidence to work with, the authors in this collection ask new questions of existing archival materials, suggest new interpretive approaches and present innovative ways to enhance sources so as to generate new stories. All contributors are engaged with the nature and processes of knowledge production, and with the politics of recognition, both past and present, a theme that is at the heart of the chapter by Catherine Bishop and Richard White.

For his chapter, Driver uses examples from a range of imperial and colonial settings, including Nepal and North America, to introduce themes and issues that are explored by other contributors whose studies focus mainly on Australia and Oceania. Driver reminds us that evidence of indigenous intermediaries appears unevenly in the archives, ranging from rich biographical details to little more than shadowy hints. He makes the important point that intermediaries' agency, authority and power are not indexed in any straightforward way to their archival imprint. As always, attention must be given to the contexts and conditions that structure relationships and which contribute to recognition of local people's labour and legacies. Following this is a trio of chapters that focus on Aboriginal guides who contributed to land and maritime exploration in nineteenth-century Australia. The politics and nature of the public recognition accorded to Aboriginal guides is a theme that Bishop and White examine in their contribution. Correcting a common misapprehension that Aboriginal guides received little or no acknowledgement, their study provides a useful typology of notice and reward that Aboriginal guides received. The phenomenon of 'hidden histories' they identify is less a consequence of the practices and prejudices of the explorers at the time than a result of the later habits of settler history-making, particularly the emergence of national history that denied Aboriginal people any part in the story of Australia's 'foundations'. But even here Bishop and White caution against an overly simplistic account of historical invisibility, by showing that while national histories might erase or minimise the contribution of Aboriginal guides to colonial exploration, they remained persistently popular subjects for local commemorations and histories.

Whereas Bishop and White discuss a number of Aboriginal guides, in their respective chapters Maria Nugent and Tiffany Shellam provide detailed studies of one or two. In her chapter, Nugent addresses questions about recognition, reputation and representation through a discussion of one of the most famous Aboriginal guides, Jacky Jacky. The archive is central to her analysis as she considers the ways in which the making of Jacky's testimony about the expedition in which he participated contributed to the construction of his public persona and reputation as the archetypal faithful guide. Shellam provides a study of Boongaree (known more commonly as Bungaree), another well-known Aboriginal guide, and Miago, who each accompanied maritime expeditions in the early nineteenth century. Her focus is on the mediating role they played 
in brokering relations between expeditions and local people. In a perceptive reading of descriptions of their actions and responses, she prioritises the agency of local intermediaries, recasting exploration encounters in a triangular relationship in which intermediaries were frequently in the middle.

A further collection of chapters moves beyond Australia to focus on Oceania and engage with the issue of the co-production of knowledge and the ways in which 'local' contributions become increasingly invisible over time as texts circulated beyond the places and times of their original production. Positioning local people as active shapers and co-producers in the formulation and recording of knowledge about Oceania is the focus of Douglas's chapter. She highlights the influence of local people in written and visual representations, locating 'textual residues' of indigenous interlocutors in exploration texts. Her methodological approach of searching for indigenous 'countersigns' makes visible indigenous knowledge and agency that was crucial to exploration and otherwise obscured in marginalia, word lists and cartography. Gascoigne's chapter is centrally concerned with epistemologies as he considers the ways in which European science incorporated indigenous people's knowledge acquired through encounters that occurred in the course of maritime exploration in the Pacific, but obscured or disavowed its sources through processes of generalisation and abstraction. In tracing this global history of science, Gascoigne performs a great service because as he charts it he retrieves details of the indigenous intermediaries - the collectors, the pilots, the navigators and others - who were the original if unacknowledged sources for the information on which many maps, collections and taxonomies were based. Parsons's contribution complements Gascoigne's chapter as she takes as her focus some of the maps that he mentions, in particular Tupaia's maps, to explore the collaborative methods by which they were originally produced. Parsons studies these 'texts' within the context of their production, highlighting the creative and collaborative negotiations between indigenous people and British naval men that were involved. Employing an approach to art history that understands drawing as a method of problem-solving rather than as representation, Parsons points us yet again to the collective nature of exploration and to the idea that knowledge was frequently a 'co-production' between expedition leaders and local intermediaries, while also reminding us how easy it is to forget or overlook this as historical interpretations continually fall back on ideas of independent, autonomous and self-realising action and retain a commitment to single authorship and individual authority. In another chapter focused on visual culture, Antje Lübcke examines photography and the role of the camera as a mediator in encounters in British New Guinea in the late nineteenth century. She reads the photographic archive for evidence of local people's agency and recognises their imprint in shaping the visual record through their active participation in composing photographs. 
The final chapter in the volume demonstrates an innovative approach to the archives of exploration involving contemporary and creative engagements. Collard and Palmer go beyond the textual colonial archive, utilising a Noongar and non-Noongar history practice in order to place Noongar people at the 'centre' of historical encounters between Aboriginal people and newcomers. Explorers' journals are interpreted by 'talking back' to the 'old people', adopting a Noongar hermeneutic method that is inspired by Collard's Noongar knowledge and the ways in which the 'old people' read the country and interpret the past. This chapter provides a model for engaging in creative and ethical ways with Aboriginal people and communities as collaborators and partners in the research process, and in ways that open up exploration archives to recursive readings. Along with the earlier chapters, it returns us to questions of 'the archive' itselfto histories of the making of collections and institutional repositories of the vast materials of imperial and colonial exploration, as well as to the metaphors we use to describe our approaches to them. ${ }^{27}$ As Driver reminds us in his chapter, in the archives of exploration

there is not so much a hidden layer of meaning waiting to be uncovered through the application of the scholarly equivalent of a trowel than multiple pits and channels to be worked across such materials: indeed, new layers of interpretation and new kinds of evidence (notably oral history or creative practice) may need to be added before they can be made to generate new stories, suggesting a programme of construction as much as archaeology.

The chapters included in this volume might be thought about as just some of the 'multiple pits and channels' currently being worked on across the archives of exploration, and through which new stories are being generated and by which the archives themselves are being expanded, enhanced and reconstructed. With their attention to teasing out the presence, agency and contribution of indigenous people, and to reading the archival imprints and traces of them, all of the chapters contribute in different ways to a broader scholarly project to draw indigenous history and exploration history closer together. This includes continuing to experiment with ways to write new kinds of histories of exploration, ones that do not reproduce the politics of visibility and recognition that characterises the archives of exploration, but that instead make it a central conceptual issue with which to engage. 


\section{References}

Baker, Don 1995, 'Wanderers in Eden: Thomas Mitchell compared with Lewis and Clark', Aboriginal History 19(1): 3-20.

-1998, 'Exploring with Aborigines: Thomas Mitchell and his Aboriginal guides', Aboriginal History 22: 36-50.

Ballantyne, Tony 2013, 'Strategic intimacies: knowledge and colonization in southern New Zealand', Journal of New Zealand Studies NS14: 4-18.

2015, Entanglements of Empire: Missionaries, Maori, and the Question of the Body, Auckland University Press, Auckland.

Bayly, Christopher A. 1996, Empire and Information: Intelligence Gathering and Social Communication in India, 1780-1870, Cambridge University Press, Cambridge.

Burnett, D. Graham 2002, “'It is impossible to make a step without the Indians": nineteenth-century geographical exploration and the Amerindians of British Guiana', Ethnohistory 49(1): 3-40.

Burton, Antoinette (ed.) 2006, Archive Stories: Facts, Fictions and the Writing of History, Duke University Press, Durham, NC.

Clark, Philip A. 2008, Aboriginal Plant Collectors: Botanists and Australian Aboriginal People in the Nineteenth Century, Rosenberg Publishing, Dural.

Connell Szasz, Margaret (ed.) 1994, Between Indian and White Worlds: The Cultural Broker, University of Oklahoma Press, Norman.

Driver, Felix and Lowri Jones 2009, Hidden Histories of Exploration: Researching the RGS-IBG Collections, Royal Holloway, University of London, and Royal Geographical Society (with IBG), London.

Fritsch, Kathrin 2009, "'You have everything confused and mixed up ...!" Georg Schweinfurth, knowledge and cartography of Africa in the 19th century', History in Africa 36(1): 87-101.

Kennedy, Dane 2013, The Last Blank Spaces: Exploring Africa and Australia, Harvard University Press, Cambridge, MA.

Maddison, Ben 2014, Class and Colonialism in Antarctic Exploration, 1750-1920, Pickering \& Chatto, London. 
McDonnell, Michael 2009, “Il a Epousé une Sauvagesse": Indian and Métis persistence across imperial and national borders', Moving Subjects: Gender, Mobility and Intimacy in an Age of Global Empire, Tony Ballantyne and Antoinette Burton (eds), University of Illinois Press, Urbana: 149-171.

Metcalf, Alida C. 2005, Go-Betweens and the Colonization of Brazil, 1500-1600, University of Texas Press, Austin.

Merrell, James H. 1999, Into the American Woods: Negotiators on the Pennsylvania Frontier, W.W. Norton, New York.

Murphy, Lucy 2003, 'Public mothers: Native American Metis women as Creole mediators in the nineteenth-century Midwest', Journal of Women's History 14(4), Winter: 142-166.

Roque, Ricardo and Wagner, Kim (eds) 2011, Engaging Colonial Knowledge: Reading European Archives in World History, Palgrave, London.

Schaffer, Simon, Lissa Roberts, Kapil Raj and James Delbourgo (eds) 2009, The Brokered World: Go-Betweens and Global Intelligence, 1770-1820, Science History Publications, Sagamore Beach, MA.

Shellam, Tiffany, Maria Nugent, Shino Konishi and Allison Cadzow (eds) (forthcoming), Brokers and Boundaries: Colonial Exploration in Indigenous Territory, ANU Press, Canberra.

Steedman, Carolyn 2001, Dust, Manchester University Press, Manchester.

Thomas, Martin (ed.) 2014, Expedition into Empire: Exploratory Journeys and the Making of the Modern World, Routledge, London.

White, Richard 2011 [1991], The Middle Ground: Indians, Empires and Republics in the Great Lakes Region, 1650-1850, Cambridge University Press, Cambridge. 
This text is taken from Indigenous Intermediaries: New Perspectives on Exploration Archives, edited by Shino Konishi, Maria Nugent and Tiffany Shellam, published 2015 by ANU Press, The Australian National University, Canberra, Australia. 